\title{
Toxoplasmosis in immunocompetent and immunocompromised population of Constanț, Romania
}

${ }^{1}$.Faculty of medicine, University Ovidius Constanţa, Romania

2.Clinical Infectious Diseases Hospital Constanţa, Romania

\begin{abstract}
We analyzed a total of 412 adult patients diagnosed with toxoplasmosis in the Clinical Infectious Diseases Hospital Constanta between 01Jan 2010 - 01 Jan 2015. Of these patients, $82.03 \%$ were from urban area, $74 \%$ female, majority aged 30-48 years. 3.15\% were diagnosed with HIV infection (13 patients), in four of these patients, toxoplasmosis was the primary clinical manifestation. The most common clinical manifestation in nonHIV infected patients was painless cervical adenopathy (106 patients), 49 patients had associated infection with Toxocara and in HIV infected patients prevailed cerebral toxoplasmosis (toxoplasmic encephalitis, with or without focal CNS lesions). 59 pregnant women (6 with acute infection and 53 with chronic infection) were followed during pregnancy. Reporting the number of cases of toxoplasma infection in Constanta population (254.693 inhabitants), we obtain a prevalence of 161.76 cases/ 100.000 inhabitants. Most of the patients were female and their supervision is required for possible implications in pregnancy. We believe that Toxoplasma infection is underdiagnosed in our county.
\end{abstract}

Keywords: toxoplasmosis, nonHIV infected patients, enzyme immunoassays

Irina Magdalena Dumitru

George Enescu 23, Constanţa, România

dumitrui@hotmail.com

$+40744761297$

\section{Introduction}

Toxoplasmosis, an infection with a worldwide distribution, is caused by the intracellular protozoan parasite, Toxoplasma gondii (T. gondii).

Up to a third of the world's human population is estimated to carry a Toxoplasma infection [1]. While in the United States it is estimated that $22.5 \%$ of the population have been infected with Toxoplasma [2], other studies show that in the world is very different seroprevalence: Latin America (about 50-80\%), parts of Eastern and Central Europe (about 20-60\%), the Middle East (about 30-50\%), parts of Southeast Asia (about 20-60\%), and parts of Africa (about 20-55\%) [3].In various places throughout the world, it has been shown that up to $95 \%$ of some populations have been infected with Toxoplasma. Infection is often highest in areas of the world that have hot, humid climates and lower altitudes.

Toxoplasmosis infection is asymptomatic in $80 \%$ of people. The most common sign in symptomatic patients is enlarged lymph nodes, especially around the neck.

Dormant infection persists for life and can reactivate in the immunosuppressed person.

More serious disease can develop or reactivate in immunosuppressed patients with brain, heart, eye or pulmonary involvement. Cerebral toxoplasmosis or chorioretinitis are frequent complications of AIDS 
when the lymphocyte CD4 cell count drops below 100 cells/mm3 [4].

Acute toxoplasmosis during pregnancy may lead to severe complications for the fetus.

In early pregnancy brain damage as well as liver, spleen and eye disorders may occur. Infection in late pregnancy may result in persistent eye infection through life.

\section{Aim}

The aim of the study was to evaluate the prevalence of symptomatic toxoplasmosis in Constanta, clinical manifestations in immunocompetent and immunocompromised persons. This study is a continuation of the release of Microbiology Conference [5], where partial results have been communicated

\section{Material and methods}

Were analyzed a total of 412 adult patients, diagnosed with toxoplasmosis within the Clinical Infectious Diseases Hospital Constanta between 01 Jan 2010 - 01 Jan 2015.

The reported acute toxoplasmosis cases were considered laboratory-confirmed when serologic assays indicated an acute infection.

Paired serum samples were tested using commercial enzyme immunoassays (bioMérieux, Marcy l'Etoile, France) with an automated VitekImmuno Diagnostic Assay System (VIDAS). The analyses were performed as instructed by the manufacturers.

For the IgG and IgM assays, positive results were defined as values of $\geq 8$ international units (IU)/ $\mathrm{ml}$ and index values of $\geq 0.65$. Equivocal results ranged from 4 to $8 \mathrm{IU} / \mathrm{ml}$, and index values ranged from 0.55 to 0.65 . Negative results were defined as $<4 \mathrm{IU} / \mathrm{ml}$ and index values of $<0.55$.

If the analyses of the paired serum samples revealed a significant increase in the $\operatorname{IgG}$ antibody titers or positive results from both $\mathrm{IgM}$ and $\mathrm{IgG}$ assays, then we performed a subsequent $\mathrm{T}$. gondii IgG avidity assay (bioMérieux, Marcy l'Etoile, France). The results were interpreted in accordance with the manufacturer's instructions. A high avidity test result excluded a recently acquired infection within 4 months of serum sampling. Low IgG avidity was defined as an index value $<0.200$, equivocal $\mathrm{IgG}$ avidity was defined as $0.200 \leq$ index $<0.300$, and high $\operatorname{IgG}$ avidity was defined as an index value $\geq 0.3$.

We applied a standardized questionnaire [6] on risk factors for infection with toxoplasma and compared with another 200 non-infected patients.

The study data were entered into an electronic database. We used Med Calc software to calculate the odds ratio for evaluated differences between case and control patients. We considered statistically significant $\mathrm{P}<0.5$.

\section{Results}

Of these 412 adult patients only 39 were diagnosed with acute infection based on laboratory protocol $(9.46 \%)$. Most of them were female, majority aged between $30-48$ years, $82.03 \%$ from urban area.

Table I - Characteristics of the patients

\begin{tabular}{|l|l|}
\hline Gender F/B (pts) & $305 / 97$ \\
\hline Age (median) (years) & 32.2 \\
\hline Urban/rural area (pts) & $338 / 74$ \\
\hline Immunocompetent pts (No) & 399 \\
\hline HIV infected pts (No) & 13 \\
\hline Pregnant female (No) & 59 \\
\hline Toxocara positive (pts) & 49 \\
\hline
\end{tabular}

Patients $=$ pts 
The most common clinical manifestation in nonHIV infected patients was painless cervical adenopathy (106 patients), followed by flulike symptoms and generalized lymphadenopathy (8 patients), retroperitoneal and mesenteric lymphadenopathy with abdominal pain (8 patients), seizures, persistent headache (34 patients), retinochoroiditis (14 patients), pulmonary involvement (4 patients), cerebral toxoplasmosis (mass lesions) only in a female with chronic hepatitis $\mathrm{B}$ and nonHodgkin lymphoma (Table II).

Table II - Clinical manifestations of toxoplasmosis in immunocompetent patients

\begin{tabular}{|l|c|c|}
\hline Cervical adenopathy & $106 \mathrm{pts}$ & $26.56 \%$ \\
\hline $\begin{array}{l}\text { Flulike symptoms and } \\
\text { generalized lymphadenopathy }\end{array}$ & $8 \mathrm{pts}$ & $2 \%$ \\
\hline $\begin{array}{l}\text { Retroperitoneal and mesenteric } \\
\text { lymphadenopathy }\end{array}$ & $8 \mathrm{pts}$ & $2 \%$ \\
\hline Seizures, persistent headache & $34 \mathrm{pts}$ & $8.52 \%$ \\
\hline Retinochoroiditis & $14 \mathrm{pts}$ & $3.5 \%$ \\
\hline Pulmonary involvement & $4 \mathrm{pts}$ & $1 \%$ \\
\hline Cerebral toxoplasmosis & $1 \mathrm{pt}$ & $0.25 \%$ \\
\hline Skin itching and rash & $49 \mathrm{pts}$ & $12.28 \%$ \\
\hline No clinical symptoms & $166 \mathrm{pts}$ & $41.6 \%$ \\
\hline
\end{tabular}

In HIV infected patients prevailed the cerebral toxoplasmosis (toxoplasmic encephalitis, with or without focal CNS lesions), only one patient presented generalized lymphadenopathy and pulmonary involvement.

Table III - Clinical manifestations of toxoplasmosis in HIV infected patients

\begin{tabular}{|l|l|}
\hline Cerebral toxoplasmosis & $12 \mathrm{pts}$ \\
\hline $\begin{array}{l}\text { Generalized lymphadenopathy and } \\
\text { pulmonary involvement }\end{array}$ & $1 \mathrm{pt}$ \\
\hline
\end{tabular}

A significant association was the one with Toxocara, all the 49 patients were presented to the hospital for skin itching and rash.

In all 386 patients we applied a standardized questionnaire on risk factors for infection with toxoplasma and compared the responses of these patients with another 200 noninfected patients. After informed consent was obtained, participants were asked to complete the self-administered questionnaire.

In multivariate analysis of all persons, the following factors increased the risk of $\mathrm{T}$. gondii infection: eating undercooked meat $(\mathrm{P}=0.0001)$, taste meat cooking $(\mathrm{P}=0.0002)$, drinking unpasteurized milk $(\mathrm{P}=0.0382)$ and drinking untreated water $(\mathrm{P}=$ $0.3944)$.

Table IV - Risk factors in Toxoplasmosis

\begin{tabular}{|l|c|c|c|c|}
\hline Risk factor (Yes/No & Toxoplasma positive pts & Toxoplasma negative pts & 95\% CI & P \\
\hline Contact with cat & $95 / 291$ & $49 / 151$ & $0.6765-1.4961$ & 0.9763 \\
\hline $\begin{array}{l}\text { Living on farm, } \\
\text { working with animals }\end{array}$ & $58 / 308$ & $33 / 167$ & 0.5974 to 1.5202 & 0.8398 \\
\hline Contact with soil & $64 / 312$ & $41 / 184$ & 0.5974 to 1.4185 & 0.7075 \\
\hline $\begin{array}{l}\text { Raw/undercooked } \\
\text { meat }\end{array}$ & $102 / 284$ & $22 / 178$ & 1.7671 to 4.7785 & 0.0001 \\
\hline Taste meat cooking & $153 / 233$ & $48 / 152$ & 1.4174 to 3.0507 & 0.0002 \\
\hline Unpasteurized milk & $44 / 342$ & $12 / 188$ & 1.0390 to 3.9101 & 0.0382 \\
\hline Untreated water & $24 / 362$ & $9 / 191$ & 0.6412 to 3.0875 & 0.3944 \\
\hline $\begin{array}{l}\text { Travel outside } \\
\text { Europe }\end{array}$ & $22 / 364$ & $10 / 190$ & 0.5329 to 2.4748 & 0.7240 \\
\hline
\end{tabular}


There are no recent studies on the prevalence and risk factors for toxoplasmosis in our country. In 2009, Jones [7] has communicated in a U.S. study that an elevated risk of $\mathrm{T}$. gondii infection was associated with the following factors: eating raw ground beef, eating rare lamb, eating locally produced cured, dried, or smoked meat, working with meat, drinking unpasteurized goat's milk, eating raw oysters, clams, or mussels. In Serbia [8], a major risk factor for T. gondii infection is consumption of undercooked meat, in Thailand [9] a risk factor is unclean drinking water from various sources and in Taiwan [10], raw shellfish consumption and domestic cat exposure were risk factors for T. gondii infection. Another study conducted in Iran shows that eating raw vegetables at restaurants is considered the other risk factor [11].

Given that in Constanta county (Dobrogea area) live many sheep fanciers, required testing these people to have a real evidence.

\section{Conclusion}

Reporting the number of cases of toxoplasma infection in Constanta population (254.693 inhabitants), we obtain a prevalence of 161.76 cases/100.000 inhabitants, patients with symptomatic toxoplasmosis.

Most patients were female and their supervision is required for possible implications in pregnancy. Risk factors for infection with Toxoplasma in our county were eating undercooked meat, taste meat cooking, drinking unpasteurized milk and drinking untreated water. Because in the general population $90 \%$ of people infected with Toxoplasma are asymptomatic and TOXO Seroprevalence in HIV infected patients is $78 \%$ we believe that Toxoplasma infection is underdiagnosed in our county. It requires a screening study to prevent developing complications.
1. Montoya, J.G. \& Liesenfeld, O. (2004). Toxoplasmosis. Lancet. 363(9425), 1965-1976

2. Jones, J.L., Kruszon-Moran, D., Sanders-Lewis, K. \& Wilson, M. (2007). Toxoplasma gondii infection in the United States, 1999-2004, decline from the prior decade. Am J Trop Med Hyg. 77(3), 405-410

3. Montoya, J.G., Boothroyd, J.C. \& Kovacs, J.A. (2009). Toxoplasma gondii. In Mandell, G.L., Bennett, J.E., Dolin, R. eds. Mandell, Douglas, and Bennett's Principles and Practice of Infectious Diseases, 7th ed. (chap 279). Philadelphia: Elsevier Churchill Livingstone

4. Pappas, G., Roussos, N. \& Falagas, M.E. (2009). Toxoplasmosis snapshots: global status of Toxoplasma gondii seroprevalence and implications for pregnancy and congenital toxoplasmosis. International Journal for Parasitology. 39(12), 1385-1394

5. Dumitru, I.M. (2014). Toxoplasmosis in immunocompetent and immuno compromised population of Constanta, Romania. $3^{\text {rd }}$ International Conference on Clinical Microbiology \& Microbial Genomics, September 24-26, Valencia, Spain. Abstract book.

6. Cook, A.J., Gilbert, R.E. \& Buffolano, W. (2000). Sources of Toxoplasma infection in pregnant women: European multicenter casecontrol study. European Research Network on Congenital Toxoplasmosis. BMJ.321, 142-147

7. Jones, J.L., Dargelas, V., Roberts, J., Press, C., Remington, J.S. \& Montoya, J.G. (2009). Risk Factors for Toxoplasma gondii Infection in the United States. Clin Infect Dis. 49, 878-884

8. Djokic, V., Klun, I., Musella, V., Rinaldi, L., Cringoli, G., Sotiraki, S. \& Djurkovic-Djakovic, O. (2014). Spatial epidemiology of Toxoplasma gondii infection in goats in Serbia. Geospat Health. 8(2), 479-488.

9. Andiappan, H., Nissapatorn, V., Sawangjaroen, N., Chemoh, W., Lau, Y.L., Kumar, T., Onichandran, S., Suwanrath, C. \& Chandeying, 
V. (2014). Toxoplasma infection in pregnant women: a current status in Songklanagarind hospital, southern Thailand. Parasit Vectors. 7(1), 239

10. Chiang, T.Y., Kuo, M.C., Chen, C.H., Yang, J.Y., Kao, C.F., Ji, D.D. \& Fang, C.T. (2014). Risk factors for acute Toxoplasma gondii diseases in Taiwan: a population-based case-control study. PLoS One. 9(3)

11. Jafari, R., Sadaghian, M. \& Safari, M. (2012). Seroprevalence of Toxoplasma gondii infection and Related Risk Factors in Tabriz City, Iran, 2008. J Res Health Sci. 12(2), 119-121 